\title{
Design and Fabrication of Fleixible Ceiling Fan
}

\author{
Senthil J, Saravanan M, Reeshab Ram, Avinash Khanderi, Sagar C Mojar
}

\begin{abstract}
Ceiling fan serve a dual purpose of warming or cooling air and more over is economically cheaper than AC and so it is worthy of study. Efficiency of ceiling fans depends upon RPM [rotations per minute], the height from the ceiling fan design. In our research, we would be considering the height from the ceiling and the CFM [Cubic feet per minute] of the fan to find its efficiency and as a result findings the most efficient height from the ceiling and CFM. There are two stages of experimentation we have done to get the expected results. Firstly, the height of the rod of ceiling fan is kept constant and wind speed readings are obtained by changing the area around the fan where wind blows. Secondly, for different heights of the rod again the above procedure is repeated. So we have fabricated the flexible ceiling fan rod according to the fans which we have taken for testing which are 3 blade, 4 blade, 4 blade with smaller blade size and have fabricated a flexible rod according to its weight and the air circulation. This can be altered in 3 steps according to the room size.

KEYWORDS: CFM [Cubic Feet per Minute], RPM [Rotation per Minute]
\end{abstract}

\section{INTRODUCTION}

In ceiling fans, the physics behind its working is a concept called air chill factor. Wind chill factor and evaporation work hand in hand to create a cool atmosphere under a ceiling fan. Evaporation, contrary to popular belief is actually a cooling process cooling surroundings. Hence, we feel cool when we're under a ceiling fan. Most important difference between a ceiling fan and A.C is that a ceiling fan cools you whereas the latter cools the room.

In ceiling fans, the efficiency, which is amount of output gained depending on input energy, is what is intended to find. For finding its efficiency, we would be considering its air speed and its height from the ceiling. Air speed is the speed at which air moves.

For a ceiling fan the speed with which the air is being moved by is an important factor.

\subsection{BACKGROUND}

Ceiling fans in market are very popular amoung every person because it is used on

consideration. As we see, there are many heights from which a ceiling fan is attached, but our curiosity is quenched in finding the most efficient height.

Economically A.C's are expensive compared to ceiling fans according to the research, we found the power consumed by A.C's in 1 hour and compared these values to a ceiling fan's power consumption in 1 hour, the values being as follows:

\begin{tabular}{|c|c|}
\hline \multicolumn{2}{|c|}{ Air Conditioner VS Ceiling Fan } \\
\hline \multicolumn{2}{|c|}{$\begin{array}{l}\text { Star Rating }\left(\mathrm{x}^{\wedge *}\right) \text {----Power Consumed in } 1 \text { hour } \\
\text { (Watts) }\end{array}$} \\
\hline $5^{\wedge *}$ & $1700 \mathrm{~W}$ \\
\hline $4^{\wedge *}$ & $1800 \mathrm{~W}$ \\
\hline $3^{\wedge *}$ & $1900 \mathrm{~W}$ \\
\hline Ceiling Fan & $40 \mathrm{~W}$ \\
\hline
\end{tabular}

day to day basis and people are in much use of them this has the scope of application in the industry. There are various brands that has produced different kinds of ceiling fans but with a single rod which is common for all fans (1inch rod) and here we have compared different parameters that prove why this project produces a flexible option and more prominent than any of the product which is currently present in the market.

a) Wind Chill factor: The wind chill factor is the temperature a person feels because of the wind. It is the perception of the coldness due to how the wind is blowing. The actual temperature may be $\mathrm{x}$ but because of the wind speed $y$, we may feel that the temperature is either $\langle\mathrm{x}$ or $>\mathrm{x}$. In a ceiling fan, the speed at which we set the fan makes us feel cooler/ hotter. In our research, we tried to keep the wind chill factor constant because wind chill factor is perception oriented and varies from person to person and doesn't affect efficiently directly.

b) Do ceiling fans warm or cool? They serve dual purpose: Ceiling fans serve a dual purpose of warming or cooling air. That is why they are so economical and worth studying. Ceiling fan's using wind chill factor; evaporate the air that surrounds your body faster to make you feel cooler.

This is heat loss by convection; therefore, the faster the air is moved by the ceiling fan, the cooling effect is greater. Ceiling fans warm the air by re-circulation it. As the warm air rise to the top of the room, the ceiling fan re-circulates it, thereby creating a warming effect.

c) Efficiency of a ceiling fan: The physical quantity, efficiency is defined as a level of performance that describes a process that uses the lowest amount of inputs to create the greatest amount of outputs. In simple words, efficiency is simply the process of doing more with less. Then, the question is why after so much research too we are unable to make a machine, in this case a ceiling fan, which is $100 \%$ efficient? The reason is that it is never possible to eliminate natural forces like air resistance, friction in the motor, etc. Hence, next best solution is to use a ceiling fan which transforms a major amount of the input electrical energy into mechanical energy thereby saving electrical costs.

In today's times the resources are scarce and energy is a precious commodity for the common man especially in India, hence, it is most necessary now that a ceiling fan with higher efficiency, i.e. a ceiling fan that circulates more air with lesser power consumption, is used.

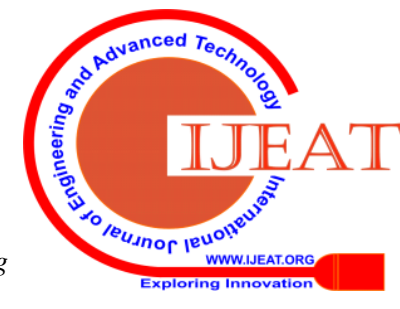




\section{Design and Fabrication of Fleixible Ceiling Fan}

d) CFM: Wind Speed is measured in the units CFM, standing for cubic feet per minute. It is a standard measurement of wind flow that indicates how many cubic feet of wind pass by a stationary point in one minute. A high CFM value indicates that more wind flows through a certain point under observation. CFM is approximately equal to 2 liters per second.

CFM of a ceiling fan is given by the equation: Wind Speed (feet per minute)*Area (square feet)

But does the efficiency depend only upon CFM and power wattage? It depends on other factors too such as revolutions per minute known as RPM, the height from the ceiling, horsepower (HP) of motor and the overall ceiling fan design. In our research, we would be considering the height from the ceiling and the CFM of the fan to find its efficiency and as a result finding the most efficient height from the ceiling and CFM. Height from ceiling is the main factor.

\section{WORK METHODOLOGY}

Infrastructure has taken a leap forward in this era and had made distances to increase exponentially and frequent, however smooth. Motivation for the project has been taken from air not circulating in all parts of the room as the room sizes vary but the fans are fixed at a certain height. Similar situation exist in numerous places. While the increasing the room size there is no air which is being spread over 4 sides of the room. We are trying to manufacture flexible ceiling fan which can be used according to the varying room sizes. As the prototype is designed for people who wants air to be circulated all around the room. For house applications like drawing room, bedroom, study room, dinning. So there is a multipurpose use of this flexible ceiling fan and be the target user.

The little cups on this device catch the wind and spin round at different speeds according to the strength of the wind. In our research, we used a Kestrel 1000 pocket anemometer

Every ceiling fan has a property known as RPM, revolutions per minute. It is the number of times the shaft of the motor rotates in a minute. The RPM varies greatly, depending on the blade size and material, the pole length and the space between the fan and the ceiling or wall.

The wattage of the ceiling fan is the power the fan consumes to run its motor. The power consumed depends on the regulator setting. If the setting is kept on 1, lower amount of power is consumed, and wattage is constant throughout the setting.

\section{PLANNING}

\section{Project Description}

The aim of our research is to find how constant wind speed of ceiling fan and area of the room where ceiling fan operates and height from ceiling of the ceiling fan (h) affect the efficiency of the ceiling fan.

The wind speed of the ceiling fan is the amount of wind passing through a foot per minute. Wind Speed is an independent variable in my experiment.

When the height from ceiling is increased/decreased, the wind speed would increase/decrease too as if ceiling fan is placed at a lower height that is closer to floor, then the wind speed is likely to be higher as opposed to height farther from floor. The instrument used to measure the wind speed or commonly known as wind speed is called an Anemometer.

The height of the rod of ceiling fan is kept constant and wind speed readings are obtained by changing the area around the fan where wind blows. Secondly, for different heights of the rod again the above procedure is repeated.

The independent variable which is changed by me is (h). According to the formula the speed, in this case, wind speed, is equal to distance, in this case, (h), divided by time, which is not being taken into consideration here as we have to explore relationship between wind speed and height from ceiling. The expected result is that as (h) increases, the wind speed would also increase. The heights from the ceiling that we have chosen are $6,9,12,15$ inches. Our first height for experimentation is 6 inches.The dependent variable is wind speed which is measured using anemometer, Kestrel 1000 pocket wind meter. Wind speed is recorded of the ceiling fan, at a height of 6 inches from ceiling, at distances ranging from $0 \mathrm{~cm}$ to 66.

\section{Data Collection and processing:}

We have used 3 different fans for the project

- Blade Ceiling Fan

- Blade Ceiling Fan

- $\quad$ Blade Ceiling Fan With Smaller Blades

\section{CONSTRAINTS AND TRADEOFFS}

\subsubsection{Realistic Constraints}

1. Economic: Cost effectiveness was necessary to bring it in application.

2. Design: - Fan Blades Size

- Height of the rod

- Minimum room size

- Hydraulic Mechanism

- Price of different fans

\subsubsection{Trade Offs}

1. The company chosen has different blade sizes and the other companies might have different blade sizes but most of the 3 blades would render to the same size only in case of 4 blade fans the design and sizes vary.

2. The room sizes could have been changed instead of square to rectangle which could have made more valuable for hall, dining rooms.

The readings of air speed obtained from anemometer are in meters per second which According to formula are to be converted into feet per minute. The conversion rate is given as 1 meter per second $=196.850394$ feet per minute

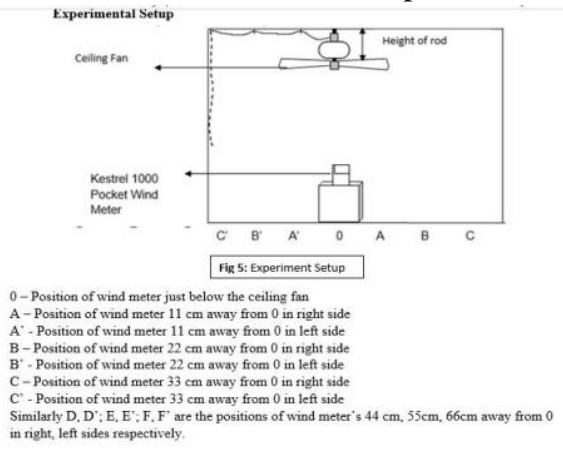

\section{BLADE CEILING FAN}

The table is for 3 blade ceiling fan sizes 6 . The results thus obtained for height from ceiling of ceiling fan for 6 inches is 


\begin{tabular}{|l|l|l|l|}
\hline $\begin{array}{l}\text { (Distance } \\
\mathbf{\pm 0 . 1}) \mathbf{c m}\end{array}$ & $\begin{array}{l}\text { Distance } \\
\text { in feet }\end{array}$ & $\begin{array}{l}\text { air } \\
\text { speed }\end{array}$ & CFM \\
\hline 0 & 0.00 & 610.23 & 0 \\
\hline 11 & 0.37 & 767.71 & 324.093 \\
\hline 22 & 0.73 & 610.23 & 1030.45 \\
\hline 33 & 1.10 & 314.96 & 1196.66 \\
\hline 44 & 1.47 & 177.16 & 1196.63 \\
\hline 55 & 1.83 & 0 & 0 \\
\hline 66 & 2.20 & 255.9 & 3889.07 \\
\hline
\end{tabular}

4 BLADE CELING FAN

The table is for 4 blade ceiling fan sizes 6 . The results thus obtained for height from ceiling of ceiling fan for 6 inches is

\begin{tabular}{|l|l|l|l|}
\hline $\begin{array}{l}\text { (Distance } \\
\mathbf{\pm 0 . 1} \mathbf{c m}\end{array}$ & $\begin{array}{l}\text { Distance } \\
\text { in feet }\end{array}$ & $\begin{array}{l}\text { air } \\
\text { speed }\end{array}$ & CFM \\
\hline 0 & 0.00 & 590.23 & 0 \\
\hline 11 & 0.37 & 657.71 & 304.083 \\
\hline 22 & 0.73 & 590.10 & 953.78 \\
\hline 33 & 1.10 & 280.56 & 1032.54 \\
\hline 44 & 1.47 & 155.96 & 1123.34 \\
\hline 55 & 1.83 & 0 & 0 \\
\hline 66 & 2.20 & 243.89 & 3469.27 \\
\hline
\end{tabular}

4 SMALLER BLADE CEILING FAN

The table is for 4 blade ceiling fan sizes 6 . The results thus obtained for height from ceiling of ceiling fan for 6 inches is

\begin{tabular}{|l|l|l|l|}
\hline $\begin{array}{l}\text { (Distance } \\
\mathbf{\pm 0 . 1} \mathbf{)} \mathbf{c m}\end{array}$ & $\begin{array}{l}\text { Distance } \\
\text { in feet }\end{array}$ & $\begin{array}{l}\text { air } \\
\text { speed }\end{array}$ & CFM \\
\hline 0 & 0.00 & 690.24 & 101.56 \\
\hline 11 & 0.37 & 789.09 & 350.078 \\
\hline 22 & 0.73 & 660.98 & 1034.78 \\
\hline 33 & 1.10 & 350.98 & 1105.5 \\
\hline 44 & 1.47 & 200.87 & 1237.89 \\
\hline 55 & 1.83 & 0 & 0 \\
\hline 66 & 2.20 & 300.98 & 3589.78 \\
\hline
\end{tabular}

\section{TESTING PHASE}

The testing has been done with 3 different fans which are 3 Blade, 4 Blade, 4 smaller blades. The anemometer was used to test the efficiency of the fans and there were uncertainties which occurred in the testing phase. The speed was kept in 5 speed for all the fans and tested. Tabulation and readings The reading were taken in the box with all the assumptions for calculation and the anemometer values are been calculated.

\section{FABRICATION PHASE}

In the Fabrication the reading were taken into account and the calculations were done accordingly and then for the flexible ceiling fan we have thought of fabricating according to the measurement and the ceiling fan weight. So we have taken MS rod of different diameter and cut it into $14 \mathrm{~cm}$ each which is a good referral length according to the fan.

The rod then has been cut with the lathe for the perfection of the edges and accuracy. For fabricating as a flexible rod the dia meter of both the rods should be different and the thickness also we have chosen in such a way that the rod fits exactly into the other rod and does not create any vibration or wobbling between the rods. Also the rods have been cut into same length for both to check the accuracy between both of them and to calculate and drill the holes in the rod.

The rod has been then drilled according to the size of the bolt and nut which is given with the fan in the box. Also the other holes are drilled with the same size. Once the drilling process was completed we had to do the paint job and marking so that it is easy for the customer to read and understand which is suitable for which size.

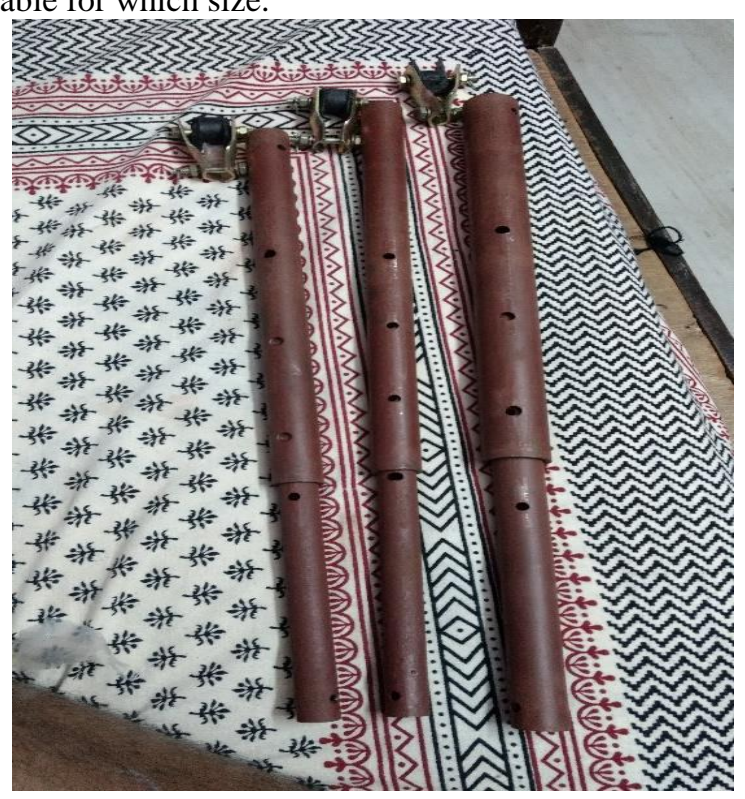

Finally the three different flexible rods were fabricated and has started the testing again with this to check if the rods are stable and are able to bear the weight of the fan. So once the testing is made it is easier for the people to identify and check.

\section{CONCLUSION}

Comparing the distance from the ground to the CFM of the ceiling fan has brought out a definite trend. It shows and hence proves that irrespective of height of rod chosen, the CFM displayed is uniform and in accord with distance taken into consideration. Hence, height of rod, from ceiling, of the fan is not affecting the CFM value. But height of the rod used is influencing amount of air a ceiling fan can rotate viz. CFM. . With this it can come to a conclusion that minimum height of the rod is more than 3 inches and maximum height of the rod is 15 inches for the living room. In these the best height for high wind speed is 9 inches. Because wind speed is not zero in any one of the distances except directly below the fan and CFM is maximum at the distance of $66 \mathrm{~cm}$.

The trend of the air flow velocities is another fascinating observance as it is in increasing fashion until the 6th observation in all cases but suddenly in the 6th observation it almost, again over all observations, reaches a 0.0 . This is the observation for the fan where it is reaching its minimum in terms of air flow. But, the most interesting observation here is that on the 7th that is last observation there is a sudden and rapid increase in air flow. The best reasoning for this would be that the air thus circulated by the wings of the ceiling fan is reaching the walls of the room and again the air is getting reflected and this is resulting in a higher last value. This trend can be generalized by saying that in proportion to the size of the room your ceiling fan is in, it would give air flow up till a certain point then it would drop to nil and suddenly at the corners of your room, it would supply air. Hence, a rod of height of 9 inches would be ideal as it is most efficient and gives maximum CFM.

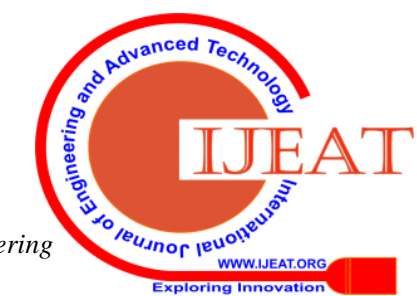




\section{Design and Fabrication of Fleixible Ceiling Fan}

\section{REFERENCES}

1. http://bugclub.org/beginners/processors/ cfm.html

2. http://science.howstuffworks.com/nature/

3. climate-weather/atmospheric/question $70 . \mathrm{htm}$

3. http://www.investopedia.com/terms/

4. E/efficiency.asp\#axzzlezEdhuXk

5. http://energycenter.org/index.php/technical-assistance/energy-efficie ncy/energy-efficiency-definition

6. http://www.ren27.dial.pipex.com/cloudsrus/measurewind.html

7. http://www.nkhome.com/kestrel/kest rel-1000/

8. http://www.businessdictionary.com/d

8. http://www.businessdictionary.com/d

9. http://www.csnceilingfans.com/Ceili

ng-Fan-Encyclopedia-A146.html

10. https://www.google.com/search?aq=

11. $1 \&$ oq=meters+per+second+to+feet+per+\&g

$\mathrm{cx}=\mathrm{w} \&$ sourceid $=$ chrome $\& \mathrm{ie}=\mathrm{UTF}-8 \& \mathrm{q}=$ meters + per+second + to+feet + per+minute 